\title{
"A Comparative Study on Effectiveness of Taping \& TENS on a Painful Shoulder in Patient with Acute Stroke"
}

\author{
Madhusudan Tiwari ${ }^{1 *}$, Monika Saini ${ }^{2}$ and Yogesh Goswami ${ }^{3}$ \\ ${ }^{1}$ Associate Professor \& In charge Dean, Nootan College of Physiotherapy, Sankalchand Patel University, India \\ ${ }^{2} M P T$ (Scholar), India \\ ${ }^{3}$ Senior Physiotherapist Prem Niketan Hospital, India
}

Submission: October 30, 2017; Published: March 22, 2018

*Corresponding author: Madhusudan Tiwari, Associate Professor \& In charge Dean, Faculty of Physiotherapy, Nootan College of Physiotherapy, Sankalchand Patel University, Visnagar, Gujarat, India, Email: madhusudan1977@gmail.com

\begin{abstract}
Objectives: to investigate the efficacy of Taping technique VS low TENS along with conventional therapeutic exercises in reduction of shoulder pain in sub acute stroke. Study design: Comparative case control study.

Methodology: Thirty subjects (both male and female) age group $\geq 55$ years with a diagnosis of acute stroke were selected directly from department of Physiotherapy, of Mahatma Gandhi Hospital, Jaipur and Nootan General Hospital at Nootan College of Physiotherapy Visnagar, Gujarat. These subjects were randomly assigned into two equal groups i.e. 15 subjects in each group. Group A- subjects were treated with low TENS of biphasic surge current with pulse width of 300 microseconds and frequency of $30 \mathrm{~Hz}$. Stimulation were given on the muscles attachment area of supraspinatus, middle deltoid and posterior deltoid muscles through surface electrodes for 30 minutes in each day and total 5 days in a week for 6 weeks. Group B- subjects were treated with taping techniques for 6 weeks and re-taping was done on every 3-4 days. Taping method -participant seated with the arm by the side in neutral posture with scapulae in retracted, depressed posture. Using hypoallergenic tape, lay the tape from coracoid process posteriorly across the lateral aspect of the acromion to a point just lateral to the T7 spinous process. Using rigid tape of $4 \mathrm{~cm}$, lay over the hypoallergenic tape to the posterior aspect of the shoulder and finally apply a firm pressure medially to position the scapula in a retracted and depressed posture. Then cover the area to be taped with the hypoallergenic tape in the same sequence as the rigid tape to follow. Start from the middle deltoid insertion and lay the rigid tape of $4 \mathrm{~cm}$ down to just before the acromion. Then, pull firmly to a point halfway between the neck and shoulder on the upper trapezius fibres. Repeat with a second strip, starting from the posterior deltoid, overlapping the first and finishing at the same point. Then apply an anchor around the arm just above the biceps muscle and ensure that it is not too tight to compromise the circulation. Both the groups were received conventional therapeutic exercises (positioning in supine and sitting, specific therapeutic exercises for upper extremity consisting of passive range of motion and active- assisted exercises with progression to active and then resisted exercises and passive stretching) on the affected side on daily basis for 6 weeks. All the data for measurement of Pain on VAS scale were collected on day 1 before commencement of treatment, at the end of week 2 , at the end of week 4 and at the end of 6th week. Comparison between the two groups was done on Paired T test. SPSS statistical software was used for data analysis.
\end{abstract}

Results: Within the group analysis of pain score on VAS from day 1 to the end of 6 weeks in both the group, the shoulder pain decreases. However, upon intergroup analysis the level of mean difference of VAS score in pre test and post test of both the groups show more improvement in Group B (Taping technique group) than Group A. Conclusion: Taping technique is more effective than TENS in the improvement of shoulder pain in sub acute stroke patients.

Keywords: Taping technique; TENS; Subacute stroke; Visual analogue scale (VAS)

\section{Introduction}

Stroke is an acute event of cerebrovascular origin, causing focal or global neurological dysfunction lasting for more than 24 hours [1]. Stroke is defined as a sudden, non-convulsive, focal neurological deficit. In its most severe form the patient becomes hemiplegic. The neurological deficit reflects both the location and size of the infarct or hemorrhage. Hemiplegia stands as the classic sign of all cerebro vascular disease [2]. Common impaiments after stroke are Somato-sensory deficits, Motor deficits, Visual deficits, abnormal synergy patterns, altered muscle activation patterns, disturbance in postural control and balance, Speech and language disorder, Perceptual disorder, Cognitive dysfunction, Dysphasia etc.

Stroke leaves the affected patients with such severe morbidity like motor loss and abnormal motor planning and poor co-ordination that quality of life deistically require prolonged period of rehabilitation. Both basic and clinical studies suggest that post-stroke motor recovery or motor relearning of the paretic limb may be maximized by the active repetitive use of 
the affected limb [3-8]. Various neuro-physiological approaches include proprioceptive neuromuscular facilitation technique (PNF), Bobath's neuro developmental approach; Brunmstorm's technique and Rood's approach are used for the rehabilitation of stroke pateients. Each of these techniques tries to facilitate recovery of motor control through different strategies. They can be integrated and used based on the requirements of the patient, experience of the therapist and stage of motor recovery. Leandri [9] reported that functional motor capacity of the paretic extremity can be improved by stimulation with low TENS and concluded that stimulation by means of low TENS could be valuable complement to the usual training of arm and hand function in the rehabilitation of stroke patients. Shoulder taping is one of the interventions that have been used in the management of shoulder subluxation in patients who have had a CVA. Taping is the use of the tape applied to the body to provide structural support. Pillastrini et al. [10] conducted study on painful hemiplegic shoulder by using neuromuscular taping and concluded that Taping is helpful in decreasing pain \& increasing ROM in subjects with shoulder pain after a stroke. TENS is a useful measure to decrease pain and to improve motor function in 3-6 months post stroke patients. Use of both taping and sling resulted in reduction of shoulder pain in the stroke patients. But some studies have shown that taping put to the limb in a poor position are likely to cause soft tissue contracture and have a deleterious effect on symmetry, balance and body image when used to reduce shoulder subluxation after stroke. Therefore need of this study was to investigate effectiveness of Taping technique along with conventional therapeutic exercises in reduction of shoulder pain in sub acute stroke and its comparison with use of low TENS administered in the other group.

\section{Material \& Methods}

\section{Sampling}

A sample of convenience of 30 subjects (both male and female) age group $\geq 55$ years, suffering from acute stroke were recruited in department of Physiotherapy, of Mahatma Gandhi Hospital, Jaipur and Nootan General Hospital at Nootan College of Physiotherapy Visnagar, Gujarat. Those who fulfilled the inclusion criteria were asked to sign an informed consent form.

\section{Research design}

An experimental design of study. Pre and post test comparative study. Thirty short listed patients were randomly assigned in the two equal groups i.e. 15 subjects in each group. Group A- Subjects received TENS [transcutaneous electrical nerve stimulation] along with conventional therapeutic exercises. Group B- Subjects received Taping techniques along with conventional therapeutic exercises.

\section{Procedure}

Group A- subjects were treated with low TENS of biphasic surge current with pulse width of 300 microseconds and frequency of $30 \mathrm{~Hz}$. Stimulation were given on the muscles attachment area of supraspinatus, middle deltoid and posterior deltoid muscles through surface electrodes for 30 minutes in each day and total 5 days in a week for 6 weeks. Group B- subjects were treated with taping techniques for 6 weeks and re-taping was done on every 3-4 days. Taping method-participant seated with the arm by the side in neutral posture with scapulae in retracted, depressed posture. Using hypoallergenic tape, lay the tape from coracoid process posteriorly across the lateral aspect of the acromion to a point just lateral to the T7 spinous process. Using rigid tape of $4 \mathrm{~cm}$, lay over the hypoallergenic tape to the posterior aspect of the shoulder and finally apply a firm pressure medially to position the scapula in a retracted and depressed posture. Then cover the area to be taped with the hypoallergenic tape in the same sequence as the rigid tape to follow. Start from the middle deltoid insertion and lay the rigid tape of $4 \mathrm{~cm}$ down to just before the acromion. Then, pull firmly to a point halfway between the neck and shoulder on the upper trapezius fibres. Repeat with a second strip, starting from the posterior deltoid, overlapping the first and finishing at the same point. Then apply an anchor around the arm just above the biceps muscle and ensure that it is not too tight to compromise the circulation.

Both the groups were received conventional therapeutic exercises (positioning in supine and sitting, specific therapeutic exercises for upper extremity consisting of passive range of motion and active- assisted exercises with progression to active and then resisted exercises and passive stretching) on the affected side on daily basis for 6 weeks. All the measurements were taken on day 1 before commencement of treatment, at the end of week 2, at the end of week 4 and at the end of $6^{\text {th }}$ week. Comparison between the two groups was done on Paired T test. SPSS statistical software was used for data analysis.

\section{Result}

\section{Within the group comparison of pain [Group-A]}

Group A: The mean value for pain measured using Visual analogue Scale of participants in the Group A during various stages of the study came out to be $8.40 \pm 1.183$ for week 0 , $6.80 \pm 1.082$ for week $2,5.67 \pm 1.113$ for week 4 and $3.87 \pm 1.506$ for week 6 . Within the group comparison of values of VAS was done using paired t-test, with level of significance, p set at 0.05 . The comparison of VAS readings for pain at various stages of group A, was found to be statistically significant (0.0001) Figure 1.

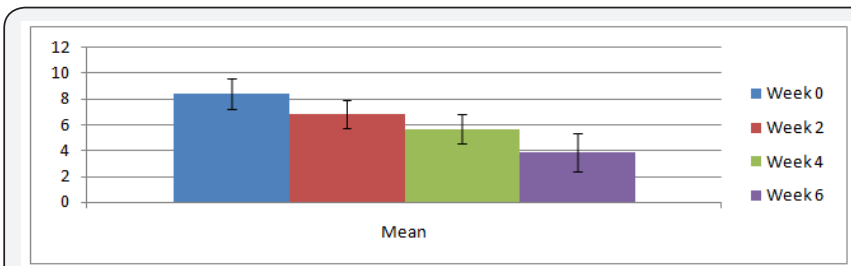

Figure 1: Within the group comparison of pain [Group-A]. 


\section{Within the group comparison of pain [Group-B]}

Group B: The mean value for pain measured using Visual analogue Scale of participants in the Group B during various stages of the study came out to be $8.00 \pm 1.069$ for week 0 , $5.47 \pm 1.125$ for week $2,5.00 \pm 1.069$ for week 4 and $2.80 \pm 0.775$ for week 6 . Within the group comparison of values of VAS was done using paired t-test, with level of significance, p set at 0.05 . The comparison of VAS readings for pain at various stages of group B, was found to be statistically significant (0.0001) except for the change in values in week 2 and week 4 with a $p$ value of 0.110 Figure 2 .

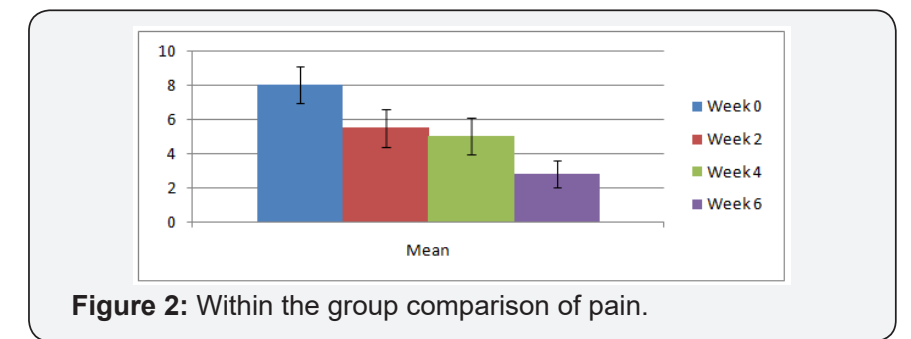

\section{Between the group comparison of pain}

At Week 2: The mean value for pain measured using Visual analogue Scale of participants in the Group A \& B measured after the $2^{\text {nd }}$ week came out to be $6.80 \pm 1.082$ and $5.47 \pm 1.125$ respectively. Between the group comparison of values of VAS was done using paired t-test, with level of significance, $p$ set at 0.05 . The comparison of VAS readings for pain between Group A and $B$, was found to be statistically significant $(0.0001)$ with a $p$ value of 0.004 Figure 3.

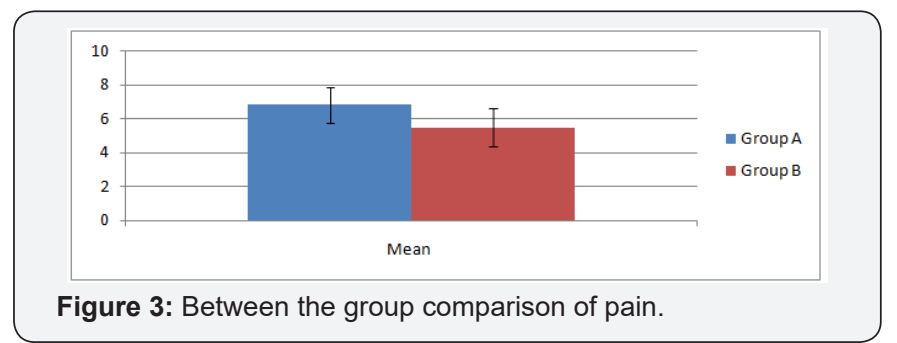

At Week 4: The mean value for pain measured using Visual analogue Scale of participants in the Group A \& B measured after the $4^{\text {th }}$ week came out to be $5.67 \pm 1.113$ and $5.00 \pm 1.069$ respectively. Between the group comparison of values of VAS was done using paired t-test, with level of significance, $p$ set at 0.05 . The comparison of VAS readings for pain between Group A and $B$, was not found to be statistically significant $(0.0001)$ with a $\mathrm{p}$ value of 0.116 Figure 4 .

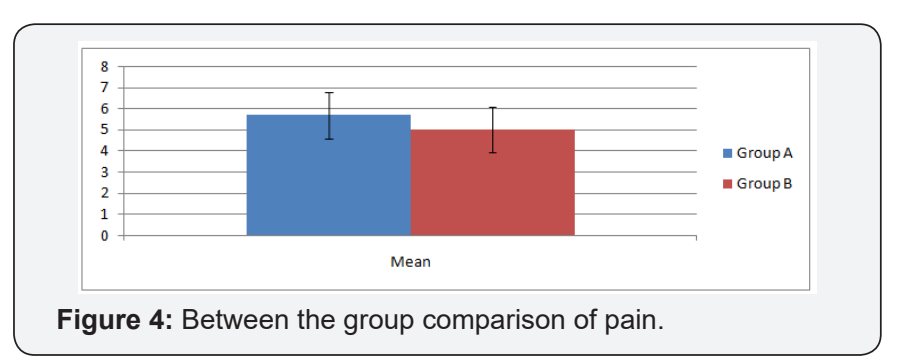

At Week 6: The mean value for pain measured using Visual analogue Scale of participants in the Group A \& B measured after the $4^{\text {th }}$ week came out to be $3.87 \pm 1.506$ and $2.80 \pm 0.775$ respectively. Between the group comparison of values of VAS was done using paired t-test, with level of significance, $p$ set at 0.05 . The comparison of VAS readings for pain between Group A and $B$, was not found to be statistically significant $(0.0001)$ with a p value of 0.056 Figure 5 .

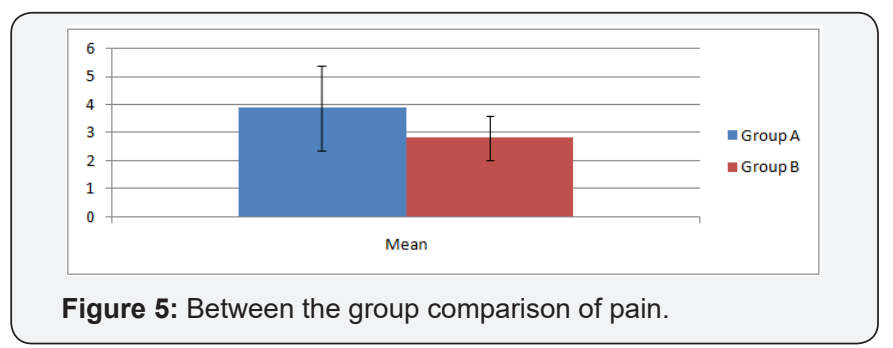

\section{Discussion}

There are several studies conducted on painful hemiplegic shoulder by using taping techniques \& TENS, most of the study concluded that taping techniques and TENS are useful in reduction of pain. Jaraczewska \& Long [11] examined the taping in stroke, improving functional use of the upper extremity in hemiplegia, and concluded that the use of taping method in conjunction with an established rehabilitation program may play an important role in the reduction of post stroke shoulder pain, soft tissue inflammation, muscle weakness, and postural malalignment.

Ancliffe [12] has done a pilot study to determine the effectiveness of a strapping technique to prevent the onset of shoulder pain in the hemiplegic upper limb of patients following a Cerebrovascular Accident (CVA). This pilot study demonstrated that tapping the affected shoulder following CVA did delay the onset of shoulder pain [13].

A study to compare high intensity and low intensity transcutaneous electrical nerve stimulation versus placebo effect was conducted in 1990 by Leandri [9]. It was found that there was significant improvement in passive range of motion (PROM) in high intensity stimulation group. Lucie Brosseau et al. 2006, had done a study to create guidelines for 13 types of physical rehabilitation interventions used in the management of adult patients presenting with hemiplegia or hemiparesis following a single cerebrovascular accident. They concluded that shoulder Subluxation should be managed with Transcutaneous electrical nerve stimulation.

The results of our study show the significant difference for improvement in shoulder pain both in Group A and Group B separately. The level of mean difference in pre test and post test of both the groups show more improvement in Group B (Taping technique group) than Group A. Taping therapy play an important role in the improvement of shoulder pain in sub acute stroke patients. 


\section{Limitations}

Disadvantages of Taping were not considered. Long term effects of Taping were not known. The outcome measures were only VAS, the subject's physical activity level and variables like BMI, functional limitation and environmental factors were not considered. Therefore further study with large sample size and combination of both the techniques can be done in future.

\section{Conclusion}

In conclusion, the present study provides an evidence to support the use of Taping method on post stroke shoulder pain as an adjunct with Conventional neuro-rehabilitation programme. The clinical and statistical analysis was observed after the 6 weeks of intervention. Therefore Taping method can be incorporate with other therapies to effectively reduce pain after stroke.

\section{References}

1. O'Sullivan SB, Schmitz TJ (2001) Physical rehabilitation assessment and treatment. ( $4^{\text {th }}$ edn), Jaypee Brothers Medical Publishers, India.

2. De Boorder MJ, Van der Grond J, Van Dongen AJ, Klijn CJ, Jaap Kappelle L, et al. (2006) Spect measurements of regional cerebral perfusion and carbon dioxide reactivity: Correlation with cerebral collaterals in internal carotid artery occulsive disease. J Neurol 253(10): 1285-1291.

3. Feeney D, Gonazalez A, Law W (1982) Amphetamine, haloperidol and experience interact to affect rate of recovery after motor cortex injury. Science 217(4562): 855-856.
4. Nudo RJ, Milliken GW (1996) Reorganization of movement representations in primary motor cortex following focal iscemic infarcts in adult squirrel monkeys. J Neurophys 75(5): 2144-2149.

5. Nudo R, Wise B, Sifuentes F, Milliken N (1996) Neural substrates for the effect of rehabilitative training on motor recovery after iscemic infarct. Science 272(5269): 1791-1794.

6. Butefisch C, Hummelsheim, Denzler P, Mauritz K (1995) Repetitive training of isolated movements improves the outcome of motor rehabilitation of the centrally paretic hand. J Neurol Sci 130(1): 59-68.

7. Wolf S, Lecraw D, Barton L, Jann B (1989) Forced use of hemiplegic upper extremities to reverse the effect of learned nonuse among stroke and head injured patients. Exp Neurol 104(2): 125-132.

8. Taub E, Miiller N, Novack T, Cook E, Fleming W, et al. (1997) Technique to improve motor deficit after stroke. Arch Phys Med Rehabil 74(4): 347-354.

9. Leandri M, Parodi CI, Corrieri N, Rigardo S (1990) Comparison of TENS treatments in hemiplegic shoulder pain. Scand J Rehabil Med 22(2): 69-71.

10. Pillastrini P, Rocchi G, Deserri D, Foschi P, Mardegan M, et al. (2015) Effectiveness of neuromuscular taping on painful hemiplegic shoulder: a randomised clinical trial. Disabil Rehabil 38(16): 1603-1609.

11. Jaraczewska E, Long C (2013) Taping in stroke: improving functional use of the upper extremity in hemiplegia.

12. Ancliffe J (1992) Strapping the shoulder in patients following a cerebrovascular accident (CVA): a pilot study. Aust J Physiother 38(1): 37-40.

13. Bergman RA, Afifi AK, Miyauchi R (1996) Circle of Willis. Illustrated Encyclopedia of human anatomic variation.

\section{Your next submission with Juniper Publishers} will reach you the below assets

- Quality Editorial service

- Swift Peer Review

- Reprints availability

- E-prints Service

- Manuscript Podcast for convenient understanding

- Global attainment for your research

- Manuscript accessibility in different formats

( Pdf, E-pub, Full Text, Audio)

- Unceasing customer service

Track the below URL for one-step submission https://juniperpublishers.com/online-submission.php 